\title{
Effect of Post Annealing on the Structural Properties of Vanadium Oxide Thin Film Deposited by RF Sputtering
}

\author{
Kapil Gupta* and Sarvesh Kumar
}

Department of Physics, Faculty of Engineering and Technology, Manav Rachna International University, Sector-43, Faridabad - 121004, Haryana, India; kapil.fet@mriu.edu.in, sarvesh.fet@mriu.edu.in

\begin{abstract}
Objective: To deposit the highly crystalline thin film of vanadium pentoxide on Si substrate. Method: In this work, we deposited vanadium oxide thin films by RF sputtering setup. These deposited thin films were annealed at $500^{\circ} \mathrm{C}$ for 1 hour in argon atmosphere. Grazing Incidence X-Ray Diffraction (GIXRD), Raman Spectroscopy and Fourier Transform Infrared Spectroscopy (FTIR) are used to analyze structural properties of as-deposited and annealed thin films of vanadium oxide. Finding: GIXRD spectra of annealed film revealed that highly crystalline thin film of vanadium pentoxide $\left(\mathrm{V}_{2} \mathrm{O}_{5}\right)$ is obtained. The texture of the film is oriented along c- axis, perpendicular to the surface of the Si substrate and it's a, b axis are parallel to the surface of substrate. Raman Spectroscopy and FTIR results confirmed the layered structure of the annealed vanadium pentoxide thin film. After post annealing, the highly crystalline and layered structure of $\mathrm{V}_{2} \mathrm{O}_{5}$ thin film on $\mathrm{Si}$ substrate is obtained. Applications: Vanadium pentoxide thin films are used in electrochromic devices, lithium batteries, and energy storage devices and as toxic gas sensors.
\end{abstract}

Keywords: Vanadium Pentoxide $\left(\mathrm{V}_{2} \mathrm{O}_{5}\right)$, Grazing Incidence X-Ray Diffraction (GIXRD), Raman Spectroscopy, RF Sputtering

\section{Introduction}

In the futuristic technological applications, the uses of phase transition materials are important. Vanadium oxides show phase transition characteristics at different temperature. Vanadium pentoxide $\left(\mathrm{V}_{2} \mathrm{O}_{5}\right)$ is the most exotic phase transition material ${ }^{1}$ and it has the topmost oxidation state in $\mathrm{V}-\mathrm{O}$ system (oxidation state +5 ). Vanadium pentoxide is an n-type semiconductor with band gap $2.3 \mathrm{eV}$. Vanadium pentoxide undergoes a semiconductor/metal phase transition near $257^{\circ} \mathrm{C}$. Vanadium pentoxide comprised of $\mathrm{VO}_{5}$ pyramids and form alternating double chain structure.

The crystal structure of $\mathrm{V}_{2} \mathrm{O}_{5}$ contains an orthorhombic unit cell having lattice parameters $\mathrm{a}=11.51 \AA, \mathrm{b}=$ $3.563 \AA$ and $c=4.369 \AA$, belongs to $\mathrm{P}_{\mathrm{mnm}}$ space group $\underline{2,3}$. Vanadium pentoxide shows wide range of applications due to thermal stability, layered structure, wide range band gap and electro-chromic property. Thin film of $\mathrm{V}_{2} \mathrm{O}_{5}$ used $^{2,4-8}$ as counter electrode in electro chromic devices, in toxic gas detectors, electronic and optical switches, colour filters, catalyst and in high capacity lithium batteries. Vanadium pentoxide thin film also exhibit interesting electrical and optical conductivity due the presence of $\mathrm{V}^{4+}$ and $\mathrm{V}^{5+}$ valance states. $\mathrm{V}_{2} \mathrm{O}_{5}$ is a fascinating material for the energy storage device and has large ionic storage ability due to its layered structure.

It has been found that the material stoichiometry is a challenging task in the deposition of $\mathrm{V}_{2} \mathrm{O}_{5}$ thin film. $\mathrm{V}_{2} \mathrm{O}_{5}$ thin films have been prepared by various techniques-18 such as sol-gel, chemical vapour deposition, sputtering, spray pyrolysis, spin coating, electron beam evaporation and pulsed laser deposition. Among all these techniques, sputtering is used as worldwide. The advantages of sput-

*Author for correspondence 
tering includes, uniform film thickness, large deposition rate, highly adhesive film with substrate, low temperature of the target material, etc. In this method, atoms are ejected from the target due to the ion bombardment. These sputtered atoms are then deposited on the substrate to form a uniform film on it.

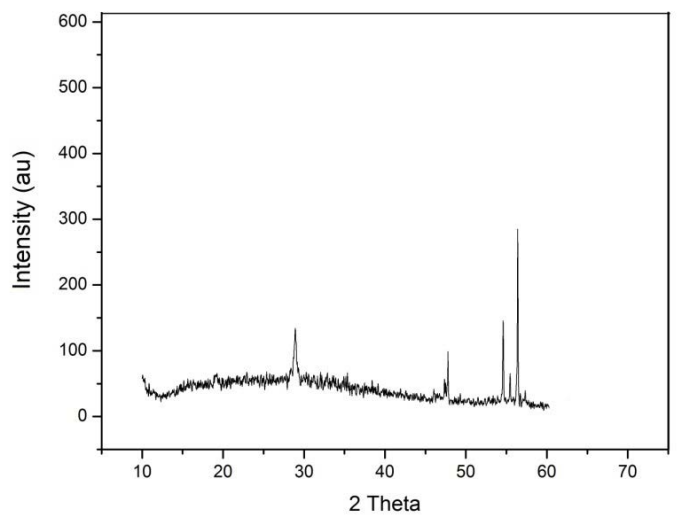

Figure 1. GIXRD Spectra of as-deposited thin film.

Nano-crystalline thin films of $\mathrm{V}_{2} \mathrm{O}_{5}$ were deposited by using RF magnetron sputtering $\underline{12}$ and found that deposited films showed the lowest refractive index in the Near Infrared Region (NIR) due to nano-crystalline structure of $\mathrm{V}_{2} \mathrm{O}_{5}$ thin films. $\mathrm{V}_{2} \mathrm{O}_{5}$ thin films were deposited $\frac{14}{}$, using spray pyrolysis and studied the electrochromic behaviour of the thin films of $\mathrm{V}_{2} \mathrm{O}_{5}$ with the applied voltage. The results of this suggested that these films are used as passive counter electrode along with active electrodes in electrochromic devices.

There are a number of techniques which can be used for deposition of vanadium oxides thin films ${ }^{2}$, the main focus was on the vanadium pentoxide thin films. Different methods of deposition were compared on the basis of band gap of $\mathrm{V}_{2} \mathrm{O}_{5}$. The uses of nano-wires and nano-rods of vanadium pentoxide in gas sensing were also reported. The effect of thermal cycling of vanadium oxide thin films was studied 17 at $300^{\circ} \mathrm{C}$. The vanadium oxide thin films were deposited by thermal evaporation technique and found the change in structure from amorphous to crystalline after thermal cycling.

The effect of substrate on vanadium pentoxide films was also examined $\stackrel{8}{ }$. Pulsed laser deposition method was used to deposit $\mathrm{V}_{2} \mathrm{O}_{5}$ films on different substrates. It was found that the films deposited on glass substrate were in amorphous nature, while on Si substrate films were highly crystalline in nature at $300^{\circ} \mathrm{C}$. The effect of deposition temperature has been reported to study the structural and optical properties of $\mathrm{V}_{2} \mathrm{O}_{5}$ thin films ${ }^{\frac{16}{6}}$. It was shown that when the substrate temperature was less than $200^{\circ} \mathrm{C}$, asdeposited thin films were amorphous in nature and when substrate temperature greater than $200^{\circ} \mathrm{C}$, well oriented crystalline film along c- axis was obtained.

In the present work, vanadium pentoxide thin films were deposited on the silicon substrate (substrate temperature $300^{\circ} \mathrm{C}$ ) using low cost $\mathrm{V}_{2} \mathrm{O}_{5}$ powder by $\mathrm{RF}$ sputtering technique. The deposited films were further annealed at $500^{\circ} \mathrm{C}$ for 1 hour in argon gas atmosphere. Structural properties of $\mathrm{V}_{2} \mathrm{O}_{5}$ thin films were analysed by the Grazing Incidence X-Ray Diffraction (GIXRD), Raman Spectroscopy and Fourier Transform Infrared Spectroscopy (FTIR).

\section{Materials and Method}

Vanadium pentoxide thin films were fabricated onto the silicon substrate by RF sputtering setup in the presence of argon atmosphere at Inter University Accelerator Centre (IUAC), New Delhi. $\mathrm{V}_{2} \mathrm{O}_{5}$ powder was crushed and pressed under the pressure of $10 \times 10^{6} \mathrm{~Pa}$ to make pellet of $2 \mathrm{~mm}$ thick and $50 \mathrm{~mm}$ diameter in size. This pellet was sintered for 2 hours at $400^{\circ} \mathrm{C}$ as the melting point of $\mathrm{V}_{2} \mathrm{O}_{5}$ is $650^{\circ} \mathrm{C}$. The sintered pellet was used as a target for $\mathrm{RF}$ sputtering setup. Acetone was used to clean silicon substrates in ultrasonic cleaner for 15 minute, after that the substrates were rinsed by deionized water thoroughly. Sputtering was carried out in argon atmosphere at working pressure $2.2 \times 10^{-2} \mathrm{mbar}$, substrate temperature $300^{\circ} \mathrm{C}$, deposition time 1 hour and RF power 120 Watt.

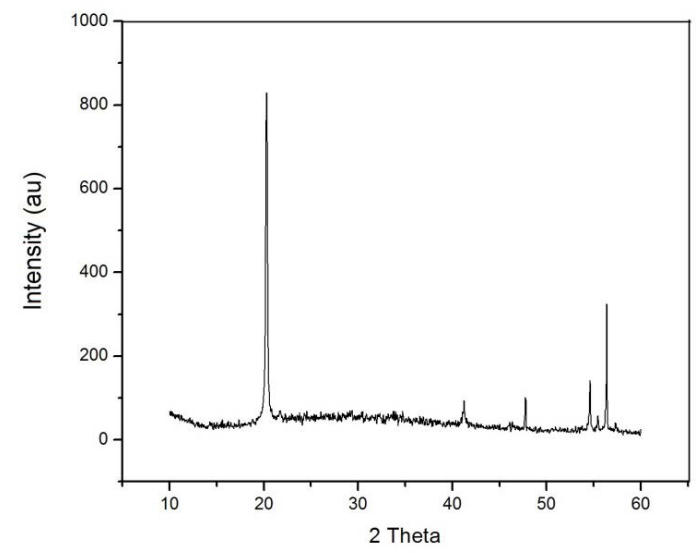

Figure 2. GIXRD Spectra of annealed thin film. 
The deposited films were annealed at $500^{\circ} \mathrm{C}$ in argon gas atmosphere for 1 hour and then cooled down to $40^{\circ} \mathrm{C}$. Grazing Incidence X-ray Diffraction (GIXRD) data was analysed to study the crystalline structure of the as-deposited and annealed thin films. The GIXRD measurements were done by using Bruker D advance X-ray diffractometer and the wavelength of X-ray was 0.154 $\mathrm{nm}\left(\mathrm{CuK}_{\alpha}\right)$. Raman Spectroscopy measurements were performed to examine the vibrational modes of $\mathrm{V}_{2} \mathrm{O}_{5}$ and Fourier Transform Infrared Spectroscopy (Bruker Tensor 37) was performed to examine the infrared transmittance of the films.

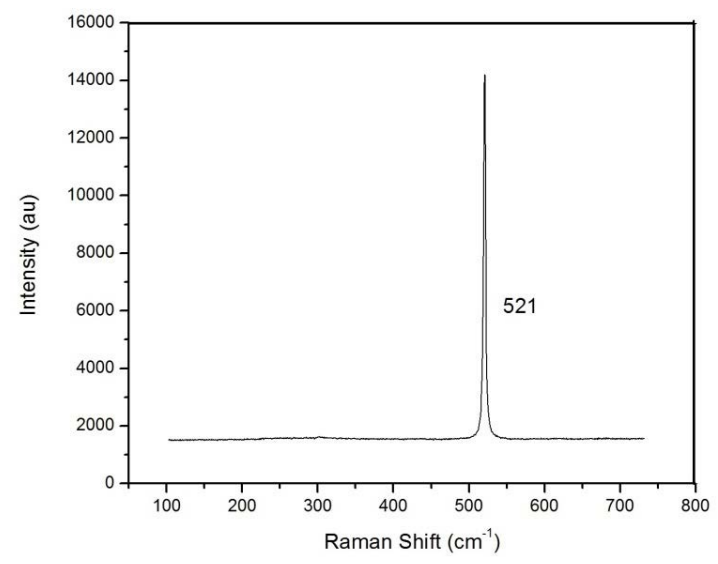

Figure 3. Raman Spectra of as-deposited thin film.

\section{Results and Discussion}

Grazing Incidence X-ray Diffraction pattern of the asdeposited thin film of vanadium pentoxide on Si substrate is shown in Figure 1. The GIXRD pattern shows the peaks corresponding to $2 \theta$ at 28.8, 47.79, 54.6 and 56.36. Peak at 28.8 may corresponds to $\mathrm{VO}_{2}(202)$ and other peaks are due to substrate $(\mathrm{Si})$. Figure 2 shows the GIXRD pattern of annealed film at $500^{\circ} \mathrm{C}$. These spectra represent the two new peaks corresponding to $2 \theta$ at 20.3 and 41 along with the peaks at $47.79,54.6$ and 56.36 . The peak corresponding to $2 \theta$ at 28.8 (as-deposited thin film) is missing and peaks at 20.3 and 41 (in figure 2) are assigned to the $\mathrm{V}_{2} \mathrm{O}_{5}$ (001) and $\mathrm{V}_{2} \mathrm{O}_{5}(002)$ respectively. These peaks confirmed about the orthorhombic symmetry of the annealed film. The as-deposited films may be represent the amorphous $\mathrm{V}_{2} \mathrm{O}_{5}$ phase, which is transform to crystalline $\mathrm{V}_{2} \mathrm{O}_{5}$ phase at $500^{\circ} \mathrm{C}$ after post annealing.

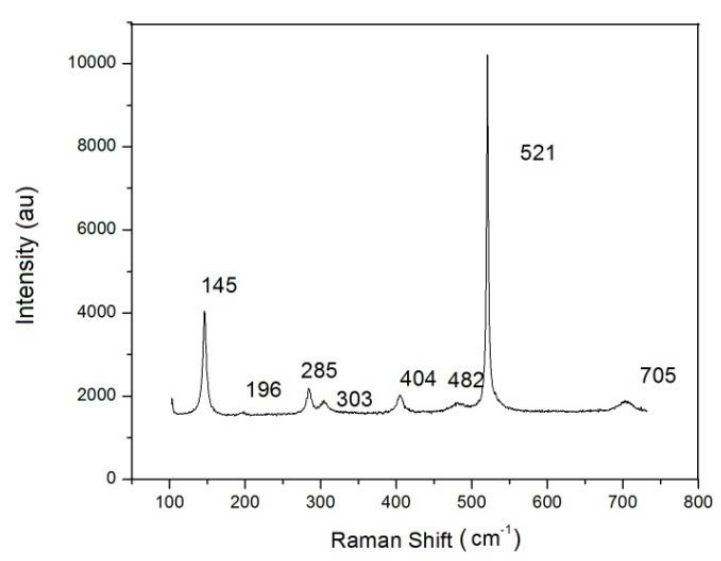

Figure 4. Raman Spectra of annealed thin film.

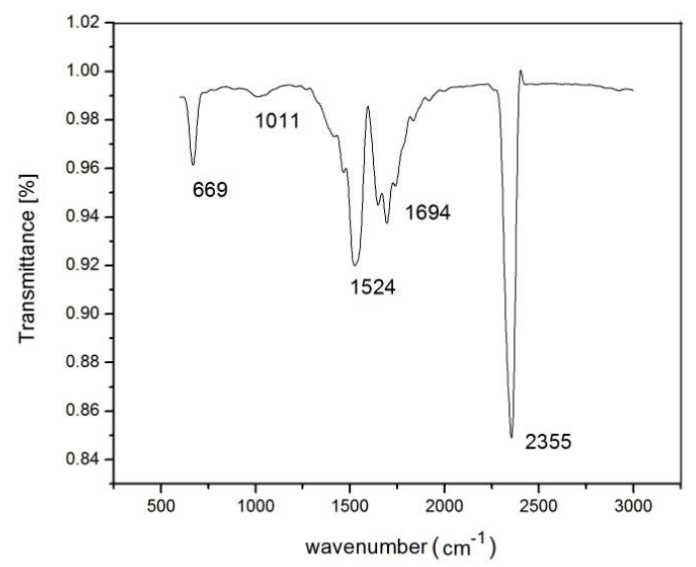

Figure 5. FTIR Spectra of annealed thin film.

Figure 3 shows the Raman spectra of as-deposited thin film on Si substrate in the wavelength range 100-800 $\mathrm{cm}^{1}$. The spectra show only one peak at 521 , which is due the substrate. Raman spectra of post annealed thin film are shown in Figure 4 in the wavelength range 100-800 $\mathrm{cm}^{-1}$. This spectra present the peaks at 145, 196285,303 , $404,482,521$ and $705 \mathrm{~cm}^{-1}$. According to the results of the theoretical factor-group analysis, 21 vibrational modes are possible in orthorhombic $\mathrm{V}_{2} \mathrm{O}_{5}$. The strong peak at $521 \mathrm{~cm}^{-1}$ corresponds to Si substrate. Peak at $705 \mathrm{~cm}^{-1}$ is the characteristic of $\mathrm{V}_{3}-\mathrm{O}$ stretching mode, the two peaks located at 404 and $285 \mathrm{~cm}^{-1}$ are due to the $\mathrm{V}=\mathrm{O}$ bending mode. The peaks located at 482 and $303 \mathrm{~cm}^{-1}$ are assigned to the bending vibration of $\mathrm{V}-\mathrm{O}-\mathrm{V}$ and $\mathrm{V}_{3}-\mathrm{O}$ bonds respectively. Prominent peak at $145 \mathrm{~cm}^{-1}$ and peak at 196 
$\mathrm{cm}^{-1}$ in Raman spectra suggest the layered structure of the $\mathrm{V}_{2} \mathrm{O}_{5}$ thin film.

Figure 5 shows the FTIR spectra of annealed thin film, dominated peaks are at 669, 1011, 1524 and 1694. Peaks at 669 and 1011 are due to $\mathrm{V}=\mathrm{O}$ stretching mode and different V-O bonds. Strongest peak at 2355 is due to the $\mathrm{Si}$ substrate. Other peaks 1524 and 1694 may be due to the reference argon gas.

\section{Conclusion}

In summary, thin film of vanadium oxide were deposited on Si substrate by RF sputtering setup, using low $\operatorname{cost} \mathrm{V}_{2} \mathrm{O}_{5}$ powder. The GIXRD and Raman spectra of the as-deposited film revealed that no clear phase of $\mathrm{V}_{2} \mathrm{O}_{5}$ is obtained, after that the as-deposited thin film was annealed in the presence of argon gas at $500^{\circ} \mathrm{C}$. The GIXRD results of post annealed thin film revealed that highly crystalline oriented film of vanadium pentoxide is obtained on silicon substrate. The structure of annealed film is such that the crystallographic c-axis is perpendicular to the substrate surface. Raman spectra of post annealed thin film also suggest that low frequency modes at 145 and $196 \mathrm{~cm}^{-1}$ are strongly related with the long range order and layered structure of vanadium pentoxide thin film. After post annealing, we obtained the highly crystalline and long range order layered structure of vanadium pentoxide thin film. Vanadium pentoxide thin film has a high ionic storage capacity and is useful in energy storage devices.

\section{Acknowledgements}

The authors would like to acknowledge the help of the Material Science group at IUAC, New Delhi for the sample preparation. The authors are grateful to UGC DAE Consortium for Scientific Research, Indore to provide the facilities for the characterization of the samples.

\section{References}

1. Morin FJ. Oxide which show a metal to insulator transition at Neel temperature. Physics Review Letters. 1959; 3 (1):3435. Crossref

2. Beke $\mathrm{S}$. A review of the growth of $\mathrm{V}_{2} \mathrm{O}_{5}$ film from 1885 to 2010. Thin Solid Film. 2011; 519(6):1761-71. Crossref

3. Darling RB, Iwanaga S. Structure properties and MEMS and microelectronic applications of vanadium oxides. Sadhana. 2009; 34(4):531-42. Crossref
4. Lu YR, Wu TZ, Chen CL, Wei DH, Chen JL, Chou WC, Dong CL. Mechanism of electrochemical deposition and coloration of electrochromic $\mathrm{V}_{2} \mathrm{O}_{5}$ nano thin films: an In Situ X-Ray spectroscopy study. Nanoscale Research Letters. 2015; 10(1):387:1-6. Crossref

5. Koduru HK, Obili HM, Cecilia G. Spectroscopic and electrochromic properties of activated reactive evaporated nano-crystalline $\mathrm{V}_{2} \mathrm{O}_{5}$ thin film grown on flexible substrates. International Nano Letters. 2013; 3(1):34:1-8. Crossref

6. Kazakova EL, Berezina OY, Kirienko DA, Markova NP. Vanadium oxide gel film: optical and electrical properties, internal electrochromism and effect of doping. Journal on Selected topics in Nano Electronics and Computing. 2014; 2(1):7-19.

7. Rao MC. Vanadium pentoxide cathode material for fabrication of all solid state lithium- ion batteries- a case study. Research Journal of Recent Sciences. 2013; 2(3):67-73.

8. Julien C, Poniatowski EH, Lopez MAC, Alarcon LE, Jarquin JJ. Growth of $\mathrm{V}_{2} \mathrm{O}_{5}$ thin film by pulsed laser deposition and their applications in lithium micro batteries. Material Science and Engineering B. 1999; 65(3):170-76. Crossref

9. Pergament AL, Kazakova EL, Stefanovich GB. Optical and electrical properties of vanadium pentoxide xerogel films: modification in electric field and the role of ion transport. Journal of Physical D: Applied Physics. 2002; 35(17):218797. Crossref

10. Bhat BA, Khan GR, Asokan K. Role of substrate effects on the morphological, structural, electrical and thermo electrical properties of $\mathrm{V}_{2} \mathrm{O}_{5}$ thin film. Royal Society of Chemistry. 2015; 5:52602-611.

11. Lee JW, Min SR, Cho HN, Chaung CW. Effect of $\mathrm{O}_{2}$ concentration on metal-insulator transition properties of vanadium oxide thin film prepared by radio frequency magnetron sputtering. Thin Solid Film. 2007; 515(2021):7740-43. Crossref

12. Esther ACM, Porwal D, Kumar MSP, Rangappa D, Sharma AK, Dey A. Optical constants of pulsed RF magnetron nanocolumner $\mathrm{V}_{2} \mathrm{O}_{5}$ coating. Physica B. 2015; 478:161-66. Crossref

13. Luo $\mathrm{Z}, \mathrm{Wu} \mathrm{Z}, \mathrm{Xu} \mathrm{X}, \mathrm{Du} \mathrm{M}$, Wang $\mathrm{T}$, Jiang Y. Impact of substrate temperature on the microstructure, electrical and optical properties of sputtered nanoparticles $\mathrm{V}_{2} \mathrm{O}_{5}$ thin film. Vacuum. 2010; 85(2):145-50. Crossref

14. Kaid MA. Characterization of electrochromic vanadium pentoxide thin film prepared by spray pyrolysis. Egyptian Journal of Solids. 2006; 29(2):273-89.

15. Patil CE, Tarwal NL, Shinde PS, Deshmukh HP, Patil PS. Synthesis of electrochromic vanadium oxide by pulsed spray pyrolysis technique and its properties. Journal of Physics D. Applied Physics. 2009; 42(2):1-6. Crossref

16. Kumar A, Singh P, Kulkarni N, Kaur D. Structural and optical studies of nanocrystalline $\mathrm{V}_{2} \mathrm{O}_{5}$ thin film. Thin Solid Film. 2008; 516(6):912-18. Crossref 
17. Wu X, Lai F, Lin L, Li Y, Lin L, Qu, Y, Haung Z. Influence of thermal cycling on structural, optical and electrical properties of vanadium oxide thin film. Applied Surface Science. 2008; 255(5):2840-44. Crossref
18. Kumar RTJ, Karunagarn B, Mangalaraj D, Narandass SK, Manoravi P, Joseph M, Gopal V. Pulsed laser deposited vanadium oxide thin film for uncooled infrared detectors. Sensors and Actuators A. 2003; 107(1):62-67. Crossref 